\title{
Antioxidant, antimicrobial, and theoretical studies of the thiosemicarbazone derivative Schiff base 2-(2-imino-1-methylimidazolidin-4-ylidene) hydrazinecarbothioamide (IMHC)
}

\author{
Ahmed A Al-Amiery*, Yasmien K Al-Majedy, Heba H Ibrahim and Ali A Al-Tamimi
}

\begin{abstract}
Background: Adverse antimicrobial activities of thiosemicarbazone (TSC) and Schiff base derivatives have widely been studied by using different kinds of microbes, in addition different methods were used to assay the antioxidant activities using DPPH, peroxids, or ntrosyl methods. However, there are no studies describing the synthesis of TSC derived from creatinine.

Results: In this study, 2-(2-imino-1-methylimidazolidin-4-ylidene)hydrazinecarbothioamide (IMHC) was synthesized by the reaction of creatinine with thiosemicarbazide. The novel molecule was characterized by FT-IR, UV-VIS, and NMR spectra in addition of the elemental analysis. The free radical scavenging ability of the IMHC was determined by it interaction with the stable-free radical 2,2"-diphenyl-1-picrylhydrazyl (or nitric oxide or hydrogen peroxide) and showed encouraging antioxidant activities. Density functional theory calculations of the IMHC performed using molecular structures with optimized geometries. Molecular orbital calculations provide a detailed description of the orbitals, including spatial characteristics, nodal patterns, and the contributions of individual atoms. Highest occupied molecular orbital-lowest unoccupied molecular orbital energies and structures are shown.
\end{abstract}

Conclusions: IMHC shows considerable antibacterial and antifungal activities. The free radical scavenging activity of synthesized compound was screened for in vitro antioxidant activity.

Keywords: antibacterial, antioxidant, antifungal, creatinine, Schiff base, thiosemicarbazone

\section{Background}

Schiff-base compounds have been used as fine chemicals and medical substrates [1]. Azomethine group $(-\mathrm{C}=\mathrm{N}-$ )-containing compounds, typically known as Schiff's bases, have been synthesized via condensation of primary amines with active carbonyls. It is well established that the biological activity of hydrazone compounds is associated with the presence of the active $(-\mathrm{CO}-\mathrm{NHN}=$ $\mathrm{C}$-) pharmacophore and these compounds form a significant category of compounds in medicinal and pharmaceutical chemistry with several biological applications that include antitumoral [2,3], antifungal [4-9], antibacterial $[10,11]$, antimicrobial [12], and anthelmintic uses

\footnotetext{
* Correspondence: dr.ahmed1975@gmail.com

Biotechnology Division, Applied Science Department, University of Technology, Baghdad 10066, Iraq
}

[13]. Schiff's base complexes play an important role in designing metal complexes related to synthetic and natural oxygen carriers $[14,15]$. Schiff bases (SBs) are important intermediates for the synthesis of some bioactive compounds such as ß-lactams [16-18], and employed as ligands for the complexation of metal ions [19]. SBs and their complexes are largely studied because they interested and important properties such as their ability to bind reversibly oxygen [20] redox systems in biological systems and oxidation of DNA [21].

Antioxidants are extensively studied for their capacity for protect organism and cell from damage that is induced by oxidative stress. Scientists in many different disciplines become more interested in new compounds, either synthesized or obtained from natural sources that 
could provide active components to prevent or reduce the impact of oxidative stress on cell $[22,23]$.

The preparation of a 2-(2-imino-1-methylimidazolidin4-ylidene)hydrazinecarbothioamide (IMHC) from thiosemicarbazide and creatinine is presented in this study. The structure established based on the extensive NMR spectroscopic studies. The microbial activities of IMHC and their in vitro antioxidant activities were also investigated. It was envisaged that these two active pharmacological molecules (thiosemicbazide and creatinine) if linked together would generate novel molecular templates, which are likely to exhibit interesting biological properties.

\section{Results and discussion Chemistry UV/visible spectra}

The UV-VIS of IMHC was recorded. The solution of IMHC in DMF exhibited two peaks at 255 and $322 \mathrm{~nm}$ (39215 and $31055 \mathrm{~cm}^{-1}$ ) which are attributed to $\pi \rightarrow \pi^{*}$ or $n \rightarrow \pi^{*}$.

\section{FT-IR spectroscopy}

The FT-IR spectra provide valuable information regarding the nature of functional group of IMHC. The appearance of a broad strong band in the IR spectra of IMHC in $3421 \mathrm{~cm}^{-1}$ is assigned to N-H stretching vibrations of the primary amine group. The spectrum of IMHC shows two different $-\mathrm{C}=\mathrm{N}$ bands at 1631 and $1618 \mathrm{~cm}^{-1}$.

Owing to the restricted rotation around the $\mathrm{C}=\mathrm{N}$ bond, the IMHC may exist into two different geometric isomeric forms. The structure determination of one representative IMHC shows (Scheme 1) that the IMHC exists in thione form and corresponds to structure where the creatinine group is cis to the hydrazinic nitrogen across the $\mathrm{C}=\mathrm{N}$ bond. The existence of the thione form predominantly in the solid state is demonstrated by the presence of two absorption bands at 1273.7 and $3421 \mathrm{~cm}^{-1}$ belonging to the $\mathrm{C}=\mathrm{S}$ and $\mathrm{NH}$ groups, respectively, and by absence of $\mathrm{SH}$.

\section{Density functional theory (DFT) studies}

DFT calculations of the IMHC (Figure 1) have been done using the optimized geometry molecular structures, Molecular orbital calculations provide a detailed

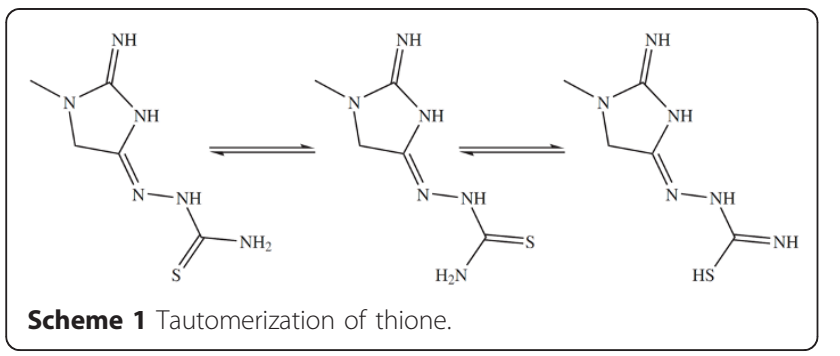

description of orbitals including spatial characteristics, nodal patterns, and individual atom contributions. The energy of highest occupied molecular orbital (HOMO) of IMHC is -0.150240 Hartree, whereas the energy of lowest unoccupied molecular orbital (LUMO) of IMHC is 0.1102540 Hartree (Table 1). The lower value in the HOMO and LUMO energy gap explains the eventual charge transfer interaction taking place within the molecules.

\section{Pharmacology \\ Antibacterial activity}

The results of antibacterial activity study for IMHC indicated that the new molecule exhibited antibacterial activity against the studied bacteria at low and high concentrations. The increased activity of the synthesized compound can be explained electron delocalization over the whole molecule. This increases the lipophilic character of the molecule and favors its permeation through the lipoid layer of the bacterial membranes. The increased lipophilic character of this molecule seems to be responsible for it enhanced potent antibacterial activity. It may be suggested that this molecule deactivate various cellular enzymes, which play a vital role in various metabolic pathways of these microorganisms (Figure 2).

\section{Antifungal activity}

According to Overtone's concept of cell permeability, the lipid membrane that surrounds the cell favors the passage of only lipid-soluble materials, so lipophilicity is an important factor controlling the antifungal activity. Delocalization of $\pi$-electrons over the IMHC increased lipophilicity facilitates the penetration of the IMHC into lipid membranes, further restricting proliferation of the microorganisms. Although the exact biochemical mechanism is not completely understood, the mode of action of antimicrobials may involve various targets in the microorganisms.

- Interference with the synthesis of cellular walls, causing damage that can lead to altered cell permeability characteristics or disorganized lipoprotein arrangements, ultimately resulting in cell death.

- Deactivation of various cellular enzymes that play a vital role in the metabolic pathways of these microorganisms.

- Denaturation of one or more cellular proteins, causing the normal cellular processes to be impaired. - Formation of a hydrogen bond through the azomethine group with the active centers of various cellular constituents, resulting in interference with normal cellular processes [24].

In vitro antifungal screening effects of the investigated compound was tested against some fungal spices 


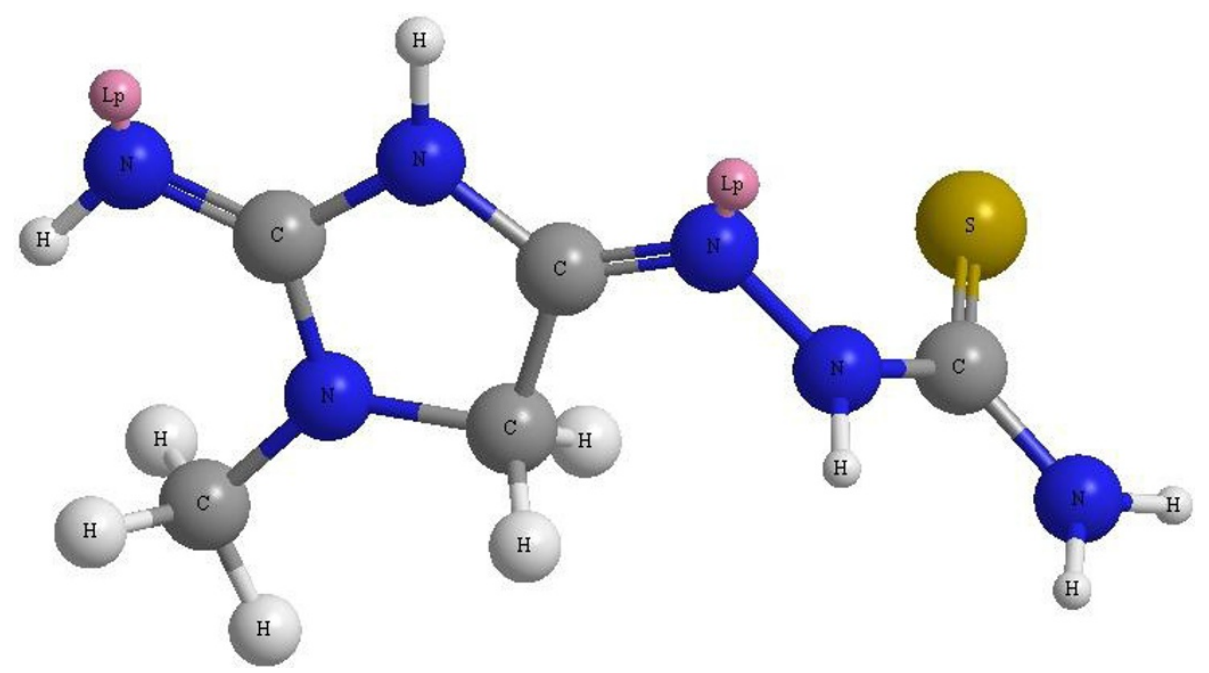

Figure 1 Optimized 3D structure of the IMHC.

(Aspergillus niger and Candida albicans). It was found to that the new compound exhibits antifungal activity against $C$. albicans more than $A$. niger (Figure 3 ).

\section{Antioxidant activity}

The role of antioxidant is to remove free radical. One important mechanism through which this is achieved is by donating hydrogen to free radicals in its reduction to an unreactive species. Addition of hydrogen would remove the odd electron feature which is responsible for radical reactivity. The hydrogen-donating activity, measured using DPPH (1,1-diphenyl-2-picrilhydrazyl) radicals as hydrogen acceptor, showed that a significant association could be found between the concentration of novel molecule and percentage of inhibition (Figure 4).

\section{Experiment}

\section{Chemistry}

\section{Matierials}

All chemical used were of reagent grade (supplied by either Merck or Fluka) and used as-received. The FTIR spectra were recorded as $\mathrm{KBr}$ disc on FTIR 8300
Shimadzu Spectrophotometer. The UV-Visible spectra were measured using Shimadzu UV-Vis. 160 A spectrophotometer. Proton NMR spectra were recorded on Bruker - DPX $300 \mathrm{MHz}$ spectrometer with TMS as internal standard. Elemental microanalysis was carried out using C.H.N elemental analyzer model 5500-Carlo Erba instrument.

\section{Synthesis of IMHC}

This mixture of hot ethanolic solution of thiosemicarbazide (1.82 g, $0.02 \mathrm{~mol}$ ) and creatinine (2-imino-1-methylimidazolidin-4-one) (2.26 g, $0.02 \mathrm{~mol})$ was refluxed with stirring for $3 \mathrm{~h}$. The completion of the reaction was confirmed by the TLC. The reaction mass was degassed on a rotatory evaporator, over a water bath. Thiosemicarbazone filtered, washed with cold EtOH, and dried under vacuum over $\mathrm{P}_{4} \mathrm{O}_{10}$. Yield, 70; M.P. $153^{\circ} \mathrm{C}$; light brown. Proton NMR $(1.8(1 \mathrm{H})$ for $\mathrm{NH}$, s. 2.2 $(3 \mathrm{H})$ for $\mathrm{CH}_{3}$, s. 2.7(2H) for $\mathrm{CH}_{2}, 8$ for $\mathrm{NH}, 9.1$ for $\mathrm{NH}$, 10.9 for $\mathrm{NH}_{2}$ ). Element chemical analysis data were $\mathrm{C}$, 32.25(31.91); H, 5.41(5.11); N, 45.13(44.74), and the reaction equation was shown in Scheme 2.

Table 1 HOMO and LUMO energy
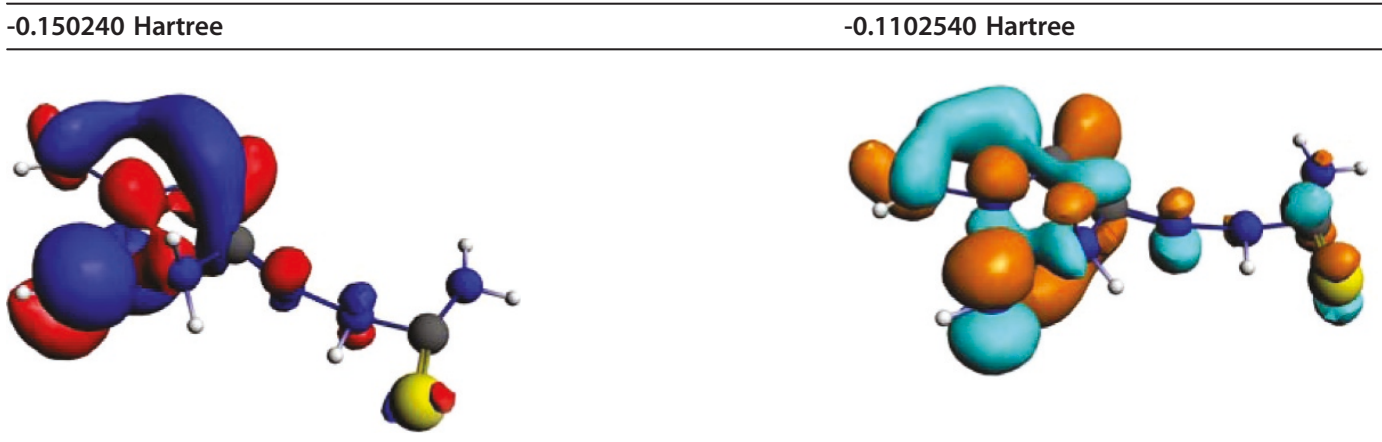


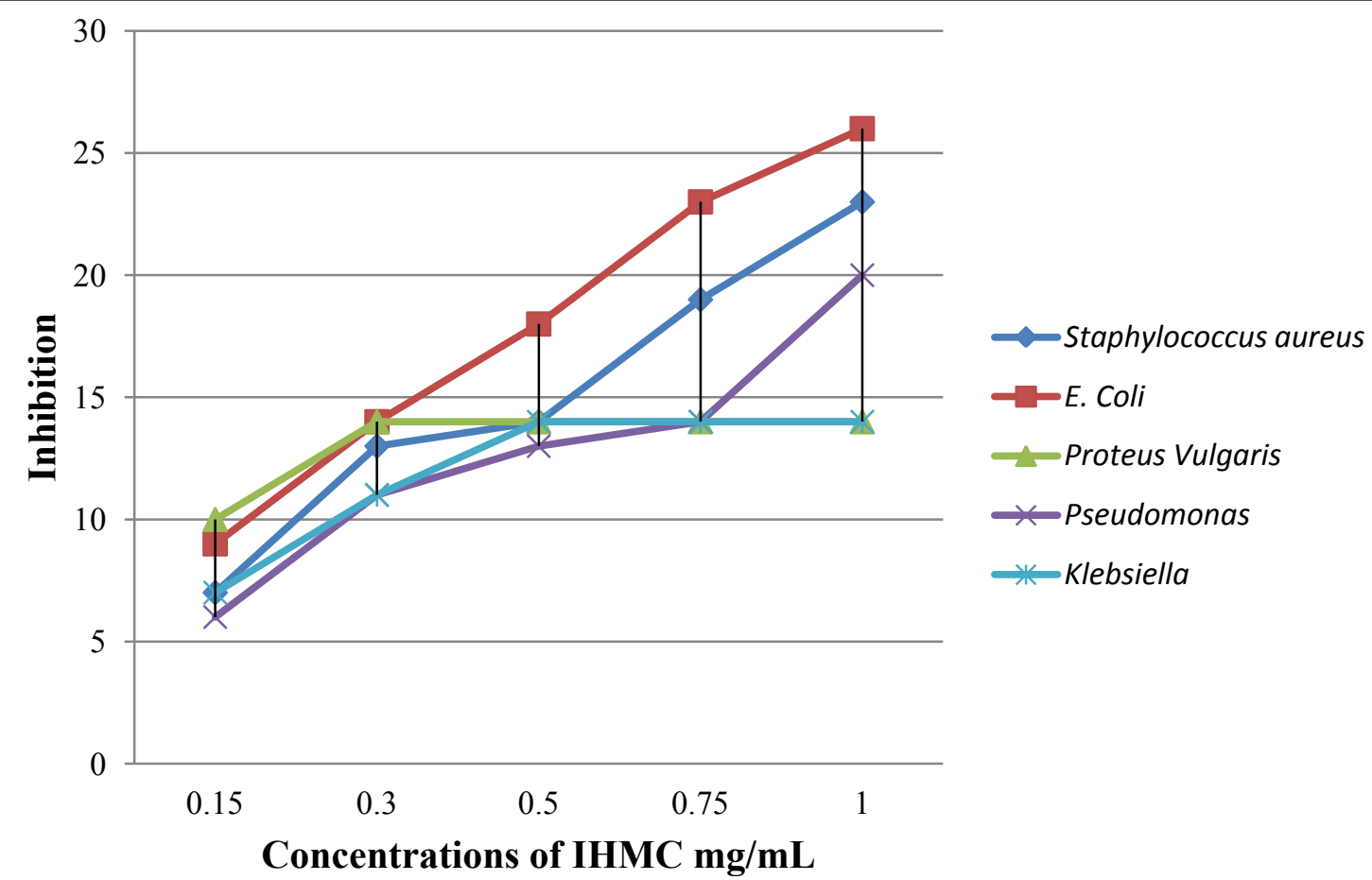

Figure 2 The effect of test organism toward synthesized compound.

\section{Pharmacology}

Antimicrobial activities

Antibacterial activity

The biological activity of the new IMHC was studied against selected types of bacteria which included positive bacteria (Staphylococcus aureus), and gram negative bacteria (Escherichia coli, Klebsiella pneumoniae, Proteus vulgaris, Pseudomonas aeruginosa), in brain hart broth agar media, which is used DMF as a solvent and as a control for the disc sensitivity test [25]. This method

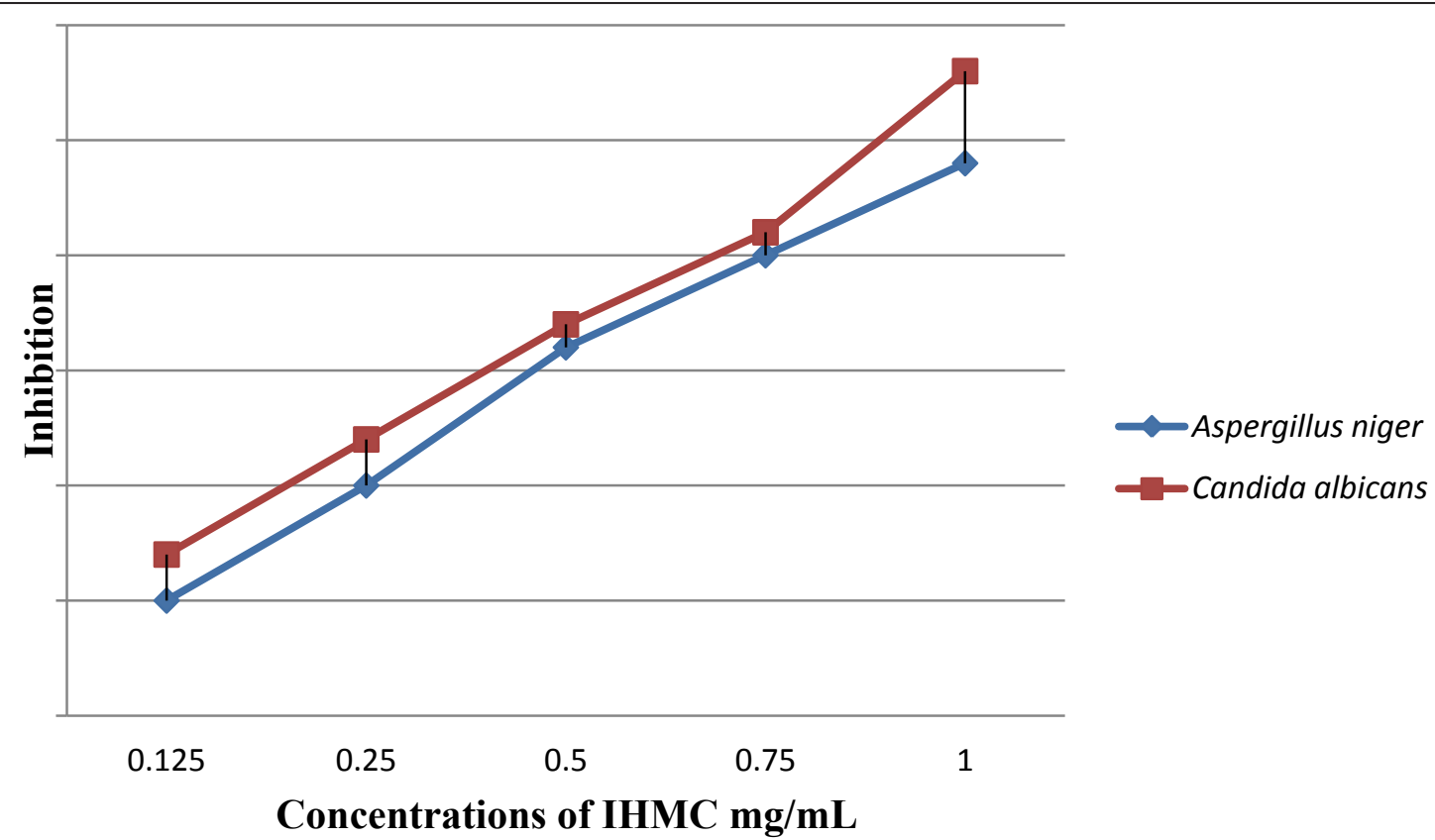

Figure 3 The effect of tested fungi toward synthesized compound. 


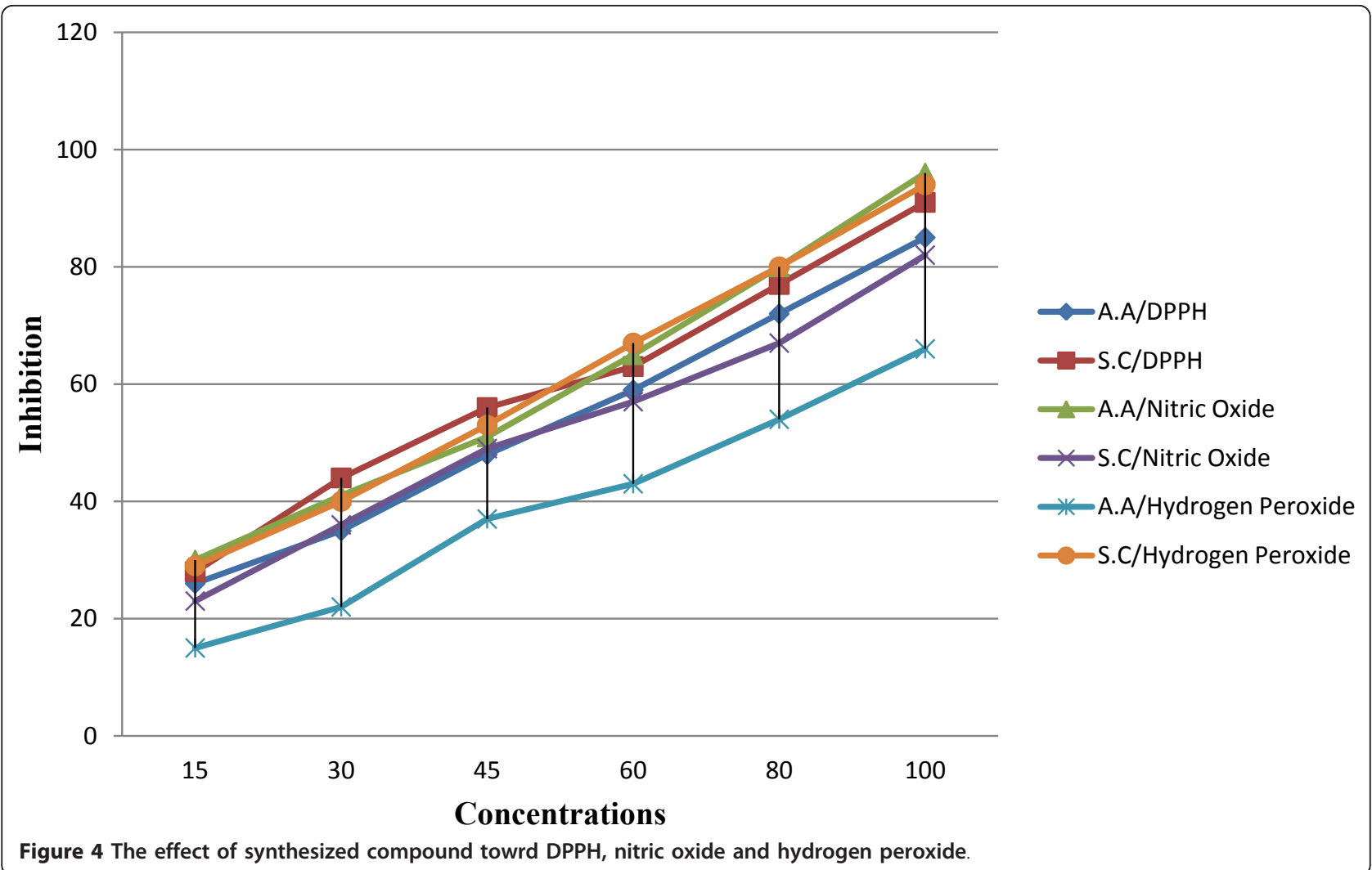

involves the exposure of the zone of inhibition toward the diffusion of microorganism on agar plate. The plates were incubated for $24 \mathrm{~h}$, at $37^{\circ} \mathrm{C}$. The antimicrobial activity was recorded as any area of microbial growth inhibition that occurred in the diffusion area.

\section{Antifungal activities}

IMHC was screened for it antifungal activity against $A$. niger and C. albicans in DMSO by serial plate dilution method using sabourand agar media. Normal saline was used to make a suspension of corresponding species. Twenty milliliters of agar media was poured in each Petri dish. Excess suspension was decanted and the plates were dried by placing in an incubator at $37^{\circ} \mathrm{C}$ for $1 \mathrm{~h} \mathrm{[15].} \mathrm{The} \mathrm{fungal} \mathrm{zone} \mathrm{of} \mathrm{inhibition} \mathrm{values} \mathrm{is} \mathrm{given} \mathrm{in}$ Figure 3 . The nutrient broth was inoculated with approximately $1 \times 10^{5} \mathrm{cfu} / \mathrm{mL}$. The cultures were incubated for $48 \mathrm{~h}$ at $35^{\circ} \mathrm{C}$ and the growth was monitored.

Hint: Sabourand agar media were prepared by dissolving peptone $(1 \mathrm{~g})$, D-glucose $(4 \mathrm{~g})$, and agar $(2 \mathrm{~g})$ in distilled water $(100 \mathrm{~mL})$ and adjusting $\mathrm{pH}$ to 5.7 .

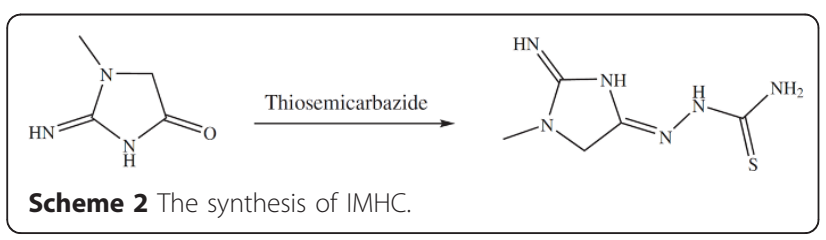

\section{Antioxidant studies}

(2,2-diphenyl-1-picrylhydrazyl) radical scavenging activity The DPPH radical scavenging activities of the test IMHC were evaluated [26]. Initially, $0.1 \mathrm{~mL}$ of IMHC at concentration of 250, 500, 750, and $1000 \mu \mathrm{g} /$ $\mathrm{mL}$ was mixed with $1 \mathrm{~mL}$ of $0.2 \mathrm{mM}$ DPPH that was dissolved in methanol. The reaction mixture was incubated in the dark for $20 \mathrm{~min}$ at $28^{\circ} \mathrm{C}$. The control contained all reagents without the sample while methanol was used as blank. The DPPH radical scavenging activity was determined by measuring the absorbance at $517 \mathrm{~nm}$ using the UV-Vis spectrophotometer. The DPPH radical scavenging activity of ascorbic acid was also assayed for comparison. The percentage of DPPH radical scavenger was calculated using Equation 1.

$$
\text { Scavenging effects }(\%)=\frac{A_{0}-A_{1}}{A_{0}} \times 100
$$

where $A_{0}$ is the absorbance of the control reaction and $A_{1}$ is the absorbance in the presence of the samples or standards.

Nitric oxide scavenging activity Sodium nitroprusside in aqueous solution at physiological $\mathrm{pH}$ generates nitric oxide spontaneously; it interacts with oxygen to produce nitrite ions, which can be estimated by the use of GriessIllosvoy reaction $[27,28]$. In this investigation, 
GriessIllosvoy reagent was modified using naphthylethylenediaminedihydrochloride $(0.1 \% \mathrm{w} / \mathrm{v})$ instead of 1 naphthylamine $(5 \%)$. The reaction mixture $(3 \mathrm{~mL})$ containing sodium nitroprusside $(10 \mathrm{mM}, 2 \mathrm{~mL})$, phosphate buffer saline $(0.5 \mathrm{~mL})$, and IMHC $(250,500,750$, and $1000 \mu \mathrm{g} / \mathrm{mL})$ or standard solution $(0.5 \mathrm{~mL})$ was incubated at $25^{\circ} \mathrm{C}$ for $150 \mathrm{~min}$. After the incubation, $0.5 \mathrm{~mL}$ of the reaction mixture containing nitrite was pipetted and mixed with $1 \mathrm{~mL}$ of sulfanilic acid reagent $(0.33 \%$ in $20 \%$ glacial acetic acid) and allowed to stand for 5 min for completing diazotization. Then, $1 \mathrm{~mL}$ of naphthylethylenediaminedihydrochloride (1\%) was added, mixed, and allowed to stand for $30 \mathrm{~min}$. A pinkcolored chromophore was formed in diffused light. The absorbance of these solutions was measured at $540 \mathrm{~nm}$ against the corresponding blank. Ascorbic acid was used as standard. Nitric oxide percentage scavenging activity was then calculated using Equation 1.

Hydrogen peroxide scavenging activity A solution of hydrogen peroxide $(40 \mathrm{mM})$ was prepared in phosphate buffer (pH 7.4). Different concentrations (250, 500, 750, and $1000 \mu \mathrm{g} / \mathrm{mL}$ ) of IMHC (or ascorbic acid) were added to a hydrogen peroxide solution $(0.6 \mathrm{~mL}, 40$ $\mathrm{mM})$. Absorbance of hydrogen peroxide at $230 \mathrm{~nm}$ was determined after 10 min against a blank solution containing phosphate buffer without hydrogen peroxide [29]. Hydrogen peroxide percentage scavenging activity was then calculated using Equation 1.

DFT

All quantum chemical calculations were performed using the DFT in the methodology. DMol3 model was employed to obtain quantum chemical parameters and optimization of the molecule geometry.

\section{Competing interests}

The HOMO-LUMO explain the presence of an isolated state within the electronic structure of the compound, which is responsible for the intense blue-violet emission. It is well-known that orbital energy differences strongly overestimate actual excitation energies, and either configuration interaction or time-dependent treatments are needed to model the energetics of the electronic excitations. Nevertheless, the orbital energies provide a useful qualitative description [29]

Received: 14 September 2011 Accepted: 2 February 2012 Published: 2 February 2012

\section{References}

1. Asiri A, Al-Youbi A, Khan S, Tahir M (2011) N-[(E)-Anthracen-9ylmethylidene]-3,4-dimethyl-1,2-oxazol-5-amine. Acta Crystallogr Sect E 67(Pt 12):03487

2. Mladenova R, Ignatova M, Manolova N, Petrova T, Rashkov I (2002) Preparation characterization and biological activity of Schiff base compounds derived from 8-hydroxyquinoline-2-carboxaldehyde and Jeffamines ED. Eur Polym J 38:989-999. doi:10.1016/S0014-3057(01)00260-9.

3. Walsh OM, Meegan MJ, Prendergast RM, Nakib TA (1996) Synthesis of 3acetoxyazetidin-2-ones and 3-hydroxyazetidin-2-ones with antifugal and antifungal and antibacterial activity. Eur J Med Chem 31:989-1000. doi:10.1016/S0223-5234(97)86178-8.
4. Singh K, Barwa MS, Tyagi P (2006) Synthesis characterization and biological studies of $\mathrm{Co}(\mathrm{II}), \mathrm{Ni}(\mathrm{II}), \mathrm{Cu}(\mathrm{II})$ ad $\mathrm{Zn}(\mathrm{II})$ complexes with bidentate Schiff bases derived by heterocyclic ketone. Eur J Med Chem 41:147-153. doi:10.1016/j. ejmech.2005.06.006.

5. Al-Amiery AA, Al-Majedy Y, Abdulreazak H, Abood H (2011) Synthesis, characterization, theoretical crystal structure and antibacterial activities of some transition metal complexes of the thiosemicarbazone (Z)-2-(pyrrolidin2-ylidene)hydrazinecarbothioamide. Bioinorg Chem Appl 2011:1-6. Article ID 483101

6. Sengupta AK, Sen S, Srivastava V (1989) Synthesis of coumarin derivatives as possible antifungal and antibacterial agents. J Ind Chem Soc 66:710-716

7. Panneerselvam P, Nair RR, Vijayalakshmi G, Subramanian EH, Sridhar SK (2005) Synthesis of Schiff bases of 4-(4-aminophenyl)-morpholine as potential antimicrobial agents. Eur J Med Chem 40:225-229. doi:10.1016/j. ejmech.2004.09.003.

8. Sridhar SK, Saravan M, Ramesh A (2001) Synthesis and antibacterial screening of hydrazones Schiff and Mannich bases of isatin derivatives. Eur J Med Chem 36:615-623. doi:10.1016/S0223-5234(01)01255-7.

9. Pandeya SN, Sriram D, Nath G, De Clercq E (1999) Synthesis antibacterial antifungal and anti-HIV activities of Schiff and Mannich bases derived from isatin derivatives and $\mathrm{N}$-[4-(4'-chlorophenyl)thiazol-2-yl]thiosemicarbazide. Eur J Pharmacol Sci 9:25-31. doi:10.1016/S0928-0987(99)00038-X.

10. Abu-Hussen AAA (2006) Synthesis and spectroscopic studies on ternary bisSchiff-base complexes having oxygen and/or nitrogen donors. J Coord Chem 59:157-176. doi:10.1080/00958970500266230.

11. Karthikeyan MS, Prasad DJ, Poojary B, Subramanya Bhat K, Holl BS, Kumari NS (2006) Synthesis and biological activity of Schiff and Mannich bases bearing 2,4-dichloro-5-fluorophenyl moiety. Bioorg Med Chem 14:7482-7489. doi:10.1016/j.bmc.2006.07.015.

12. Sharma BM, Parsania MV, Baxi AJ (2008) Synthesis of some azetidinones wih coumarinyl moiety and their antimicrobial activity. Org Chem 4:304-308

13. Husain MI, Shukla MA, Agarwal SK (1979) Search for potent anthelmintics. Part VII. Hydrazones derived from 4-substituted 7-coumarinyloxyacetic acid hydrazides. J Ind Chem Soc 56:306-307

14. Thangadurai TD, Gowri M, Natarajan K (2002) Synthesis and characterization of ruthenium(III) complexes containing monobasic bidentate Schiff bases and their biological activities. Synth React Inorg Met Org Chem 32:329-343. doi:10.1081/SIM-120003211.

15. Kadhum AH, Mohamad A, Al-Amiery AA, Takriff MS (2011) Antimicrobial and antioxidant activities of new metal complexes derived from 3aminocoumarin. Molecules 16:6969-6984. doi:10.3390/molecules16086969.

16. Aydogan F, Öcal N, Turgut Z, Yolacan C (2011) Transformations of aldimines derived from pyrrole-2-carbaldehyde and Synthesis of thiazolidino-fused compounds. Bull Korean Chem Soc 22:476-480

17. Park S, Mathur VK, Park RP, Mathur VK, Planalp RP (1998) Syntheses solubilities and oxygen absorption properties of new cobalt(II) Schiff-base complexes. Polyhedron 17:325-330. doi:10.1016/S0277-5387(97)00308-2.

18. Landy LF (ed) (1989) The chemistry of macrocyclic ligand complexes. Cambridge University Press, Cambridge

19. Zaheer M, Akhter Z, Bolte M, Siddiqi HM (2008) N-(3-nitrobenzylidene) aniline. Acta Cryst 64:2381-2382

20. Yang DP, Ji HF, Tang GY, Ren W, Zhang HY (2007) How many drugs are catecholics? Molecules 12:878-884. doi:10.3390/12040878.

21. Berners SJ (2007) Metals in medicine. Keynote Lectures. KL01: the mitochondrial cell death pathway as a target for gold and other metalbased antitumor compounds. J Biol Inorg Chem 12:S7-S52

22. Corona-Bustamante A, Viveros-Paredes J, Flores-Parra A, Peraza-Campos A, Martínez-Martínez J, Sumaya-Martínez M, Ramos-Organillo A (2010) Antioxidant activity of butyl- and phenylstannoxanes derived from 2-, 3and 4-pyridinecarboxylic acids. Molecules 15:5445-5459. doi:10.3390/ molecules15085445.

23. Dharmaraj N, Viswanathamurthi P, Natarajan K (2001) Ru(II) complexes containing bidendate Schiff bases and their antifungal activity. Transition Met Chem 26:105-110. doi:10.1023/A:1007132408648.

24. Al-Amiery AA, Mohammed A, Ibrahim H, Abbas A (2009) Study the biological activities of tribulus terrestris extracts. World Acad Sci Eng Technol 57:433-435

25. Al-Amiery AA, Musa AY, Kadhum AH, Mohamad A (2011) The use of umbelliferone in the synthesis of new heterocyclic compounds. Molecules 16:6833-6843. doi:10.3390/molecules16086833. 
26. Kadhum AH, Al-Amiery AA, Musa AY, Mohamad A (2011) The antioxidant activity of new coumarin derivatives. Int J Mol Sci 12:5747-5761. doi:10.3390/ijms12095747.

27. Garratt DC (1964) The quantitative analysis of drugs. Chapman and Hall Ltd., Tokyo,3: pp 456-458

28. Duh PD, Tu YY, Yen GC (1999) Antioxidant activity of water extract of Harng Jyur (Chyrsanthemum morifolium Ramat). Lebn Wissen Technol 32:269

29. Roof I, Park S, Vogt T, Rassolov V, Smith M, Omar S, Nino J, Loye H (2008) Crystal growth of two new niobates, $\mathrm{La}_{2} \mathrm{KNbO}_{6}$ and $\mathrm{Nd}_{2} \mathrm{KNbO}_{6}$ : structural, dielectric, photophysical, and photocatalytic properties. Chem Mater 20(10):3327-3335. doi:10.1021/cm703479k.

doi:10.1186/2191-2858-2-4

Cite this article as: Al-Amiery et al:: Antioxidant, antimicrobial, and

theoretical studies of the thiosemicarbazone derivative Schiff base 2-(2-

imino-1-methylimidazolidin-4-ylidene)hydrazinecarbothioamide (IMHC).

Organic and Medicinal Chemistry Letters 2012 2:4.

\section{Submit your manuscript to a SpringerOpen ${ }^{\mathcal{O}}$ journal and benefit from:}

- Convenient online submission

- Rigorous peer review

- Immediate publication on acceptance

- Open access: articles freely available online

- High visibility within the field

- Retaining the copyright to your article

Submit your next manuscript at $\gg$ springeropen.com 